\title{
Problem Solving Processes and Group Effectiveness on a Creative Task: A case study in Physics Education
}

\author{
Javier Pulgar ${ }^{\mathrm{a}, \mathrm{b}}$ and Alexis Spina ${ }^{\mathrm{a}}$ \\ ${ }^{a}$ Gevirtz Graduate School of Education, Univeristy of California Santa Barbara, Santa \\ Barbara, 93106-9490, CA, United States b Departamento de Fisica, Universidad del Bio Bio, \\ 4051381, Concepcion, Chile
}

\section{ARTICLE HISTORY}

Compiled October 14, 2019

\begin{abstract}
We investigated a group of physics majors solving a creative problem in the context of a course on conceptual physics and children's thinking adapted from the Physics and Everyday Thinking (PET) curriculum. In addition to learning conceptual physics, course participants discussed the ways that elementary and middle school students learn physics and their common pre-instructional ideas and models of physics phenomena. To explore group performance, research participants were asked to collaboratively design a physics learning activity with at least two questions either for elementary, middle or high school level. Participants' discussion was audio recorded, and analyzed with attention to emergent themes of the problem solving process. Next, we used a model of group effectiveness to identified the degree to which the group met the conditions for effective performance. Results suggest the group decided the content and questions for the task following a creative process where they generated ideas on the structure of the problem and its scientific narrative, while also making decision regarding targeted students age, what these would do when facing the problem, and engaged in the process of requesting ideas and information. These processes shaped the conditions for effectiveness, which enabled a deep understanding on the team's dynamic.
\end{abstract}

\section{KEYWORDS}

Problem solving, group effectiveness, physics education, student-generated questions

\section{Introduction}

Creativity and collaboration are two important pieces in today's classrooms, recognized as key competencies for life and work (Pellegrino and Hilton 2003). The conception that individuals are capable of reaching deeper learning while interacting with others, compared to what they could do in isolation (Vygotsky 1978) leads to consider group work as a key element in today's education. Collaboration plays a significant role in enhancing students' learning opportunities via communicating, analyzing, transferring and assessing their own and/or others' understandings. There is a deep dependency on personal creativity in collaboration, given that original and effective ideas (Sternberg 2012; Runco and Jaeger 2012) are rarely the product of solitary work. Instead, creative thinking is deeply social and, as Csikszentmihalyi (2013) pointed out, 
this is unlikely to occur if the person is not constantly interacting with a sociocultural context where the focus and attention is on.

Forming small groups in a large science classroom may be a common practice among teachers, and although may seem simple, educators and students must be cautious in the variables that may lead them to either positive or negative learning experience depending on their students' social abilities and motivations. The zone of proximal development (ZPD) (Vygotsky 1978) provides strong support for collaboration, particularly when students learn by interacting with more capable others. Yet, there is uncertainty on whether the others in the group are more capable and willing to collaborate.

An alternative challenge for encouraging appropriate collaboration and group processes comes from the nature of the task. In physics education tradition, math-based problems are constantly used to assess students' physics ability (Byun and Lee 2014; Kim and Pak 2002). In terms of Steiner (1966), such activities are disjunctive tasks, because when engaged in groups this can be solved by the most capable member of the team and without the necessity of further discussion. In contrast, ill-structured activities like context-rich problems (Heller and Hollabaugh 1992), or real-world problems (Fortus 2008) include higher degree of interdependency (Johnson, Johnson, and Holubec 1986) given that demand students to create and choose appropriate ideas (Rietman 1964), a task where groups are better than individuals (Baruah and Paulus 2008).

In this paper we explore the creative opportunities of a group of students solving an ill-structured problem consisting on generating a learning activity for either elementary, primary or secondary students. Secondly, we take advantage of the nature of the task to study the degree to which the group meet conditions from group effectiveness and describe them in connection with the processes and ideas proposed for solving the problem.

\section{Group Effectiveness}

Heller and Hollabaugh (1992) investigated students groups solving context-rich physics problems and identified that group size, heterogeneity and member's personality as important features that would affect group performance. Consequently, group-size does matter, being groups of three and four the ones that generated the better outcomes, which was supported by supported by Leinonen, Asikainen, and Hirvonen (2017). In terms of group composition, heterogeneous groups tend to perform better, with medium and low ability students complying an important role in regulating groups' processes, and suggesting simple but effective ideas. Harlow, Harrison, and Meyertholen (2016) found support for this claim when comparing performance of small groups on an introductory calculus-based physics class. Even in appropriate sized and mixedability groups, performance can be affected by dominant personalities who may be perceived as competent (Anderson and Kilduff 2009). To overcome these issues, researchers have attempted to assigned roles to each member Heller and Hollabaugh (1992), yet the initial plan of rotating roles relies too much on students being able to dissociate themselves from the responsibilities each role entails, from one session to the next. Further, Johnson, Johnson, and Holubec (1986) proposed two conditions that would allow students to collaborate for problem solving: positive interdependence, or students' belief that success is a collective rather than individual effort; and individual accountability, or the fact that each students assumes responsibility for mastering the 
studied material.

In addition, when students express a passive attitude in a group context, the discussion is less productive, and subsequently, the learning outcomes are diminished, which may also happen when members do not trust each other (Benckert and Petterson 2008). Along with longevity and group efficacy, these variables could contribute to team's performance Rico et al. (2008). Furthermore, finding the adequate group composition aiming for motivation to collaborate may as well increase epistemic motivation (De Dreu et al. 2011), given that a positive group climate might encourage members to identify themselves with the group, and thus actively engage in the collective problem solving process. Moreover, from the lens of learning abilities and skills, it would be expected that groups formed by students with higher levels of expertise would outperform groups formed with subjects at medium and lower levels on a given ability scale.

\subsection{Conditions for Group Effectiveness}

Based on the challenges associated with group work, we utilize a model of group effectiveness developed by Hackman (1987), which contains three elements that define effective group work in organizational contexts:

(1) 'The productive output of the group work should meet or exceed the performance standards of the people who receive and/or review the output';

(2) 'The social processes used in carrying out the work should maintain or enhance the capability of members to work together on subsequent team tasks';

(3) 'The group experience should, on balance, satisfy rather than frustrate the personal needs of group members' (p. 323)

From here, he suggested that group effectiveness should be a consequence of members' effort, knowledge and skills, and appropriate performance strategies used for the task, and summarized on the following three levels:

(1) Support effort among members: individual motivation, the task is challenging, and members feel part of the collective effort (i.e., group belonging);

(2) Support knowledge and skills: members have high task relevant skills, group shows healthy interpersonal processes, the context provides relevant educational resources, minimizing appropriate weighting of members' contributions, and fostering collective learning;

(3) Support appropriate performance strategies: group norms support selfregulation, situation scanning and strategy planning, clarity about the parameters of the performance and access to data.

Each of these conditions have been defined to motivate members to generate products that are better than the expected from the context where they work, encourage learning and competencies developed from group processes, and self-regulate members' participation aiming for healthy social interactions.

Accordingly, group effectiveness is not only a measure of the final product or solution, but also a function of the personal experience working with other team members. According to Steiner (1972), there are four individual processes that might decrease group productivity: 1 . free riding: individuals consider that the group will be able to perform well without their help; 2. production matching: individuals are constantly comparing their ideas with others; 3. evaluation apprehension: individuals monitor 
and evaluate their own ideas trying to match the quality of others' contributions; and 4. production blocking: a group dynamic leads to a reduction on the number of generated ideas. These four processes could reduce members' motivation to engage in the group task, and might strongly deteriorate the interpersonal relationships. Additional research has shown that an effective group experience is possible when members express mutual respect for other ideas and roles, in a context of healthy interactions, and with an overall sense of democracy. According to De Dreu et al. (2011), groups tend to be more creative when members express higher motivation towards reaching a deep understanding of the world -epistemic motivation (De Dreu, Baas, and Nijstad 2008). Yet, such creative performance only happens when members process information while seeking a psychologically safe climate within the team, and collective rather than individual success (De Dreu, Baas, and Nijstad 2008). De Dreu, Baas, and Nijstad (2008) suggest that pro-social motivation could be encouraged by rewarding group processes instead of individual performance within the group. In addition, the diversity of members plays a key role in determine how effective and creative groups can be, yet learning and collective performance would depend on diversity of expertise, yet this relationship is mediated by collective identification (Van Der Vegt and Bunderson 2005). Moreover, individuals tend to select teammates who are similar to themselves, enjoy good reputation as competent, and had prior experience working alongside them (Hinds et al. 2000).

Additionally, Hackman (1987) suggest that the task has to be motivationally engaging to boost collective effort. We consider that non-scripted and open-ended activities (i.e., ill-structured) would meet these conditions. Ill-structured problems lack of information that would guide individuals to find unique solutions, and therefore add higher levels of uncertainty due to a spectrum of possible outcomes, rules or strategies on how to proceed to generate them (Shin, Jonassen, and McGee 2003; Rietman 1964), elements that are likely to boost effort, and opportunities for subjects to build meaningful learning, as well as collaboration. Moreover, the nature of these assumptions would reflect understandings and familiarity with the information required for the problem (Fortus 2008).

\section{Materials and Methods}

\subsection{Research Context}

Data was collected in a course adapted from the Physics and Everyday Thinking inquiry-based curriculum (Goldberg, Robinson, and Otero 2006), grounded on the idea that learning is built over prior knowledge, requires scaffolding, may be enhanced by interaction with tools and others, and is facilitated when students are responsible for developing ideas. The content addressed in this class focused on models of magnetism, electrostatic, and forces and energy, and included opportunities for participants to engage in discussing their own learning processes, the nature of science, and physics ideas elementary and middle school students have (Harlow, Harrison, and Meyertholen 2016). The focus was oriented to improve students' awareness of previous conceptual misunderstandings, the process of how this prior knowledge could change (evolve) and become accurate scientific concepts capable of explaining the physical world.

The course attracts two different types of students with different goals. A larger group $(\mathrm{N}=23)$ of non-science majors interested in pursuing careers in elementary school teaching or related fields, and smaller group $(n=3)$ of physics majors interested in 
teaching at any level. These students come in with one to three years of undergraduate physics courses and are interested in thinking about how to help other people develop physics knowledge. The three physics majors, identified in this study as Anna, Allan and Jeff were grouped together, while the rest of the class formed groups of 3 or 4 members.

\subsection{Data Collection}

Because the study aimed to reveal the problem solving processes that involve group creativity in the context of physics problem solving, observations were focused on the group formed by the 'physics majors' due the potential richness in dialogues, arguments and mediation of physics-oriented ideas. Field notes and audio records were collected during six of the ten sessions, focusing on group interactions, members' roles, and nonverbal indicators of engagement, such as physical posture and attention to the group. The data analyzed in this paper comes from field notes and audio recordings taken during the 5th session of data collection, where the students were asked to design a learning activity using concepts of motion, force and/or energy. For this purpose, the group needed to decide on the age of the student the activity would be designed for, the physics concepts and principles to be addressed, as well as two scientific questions for 'their' students, and the narrative of the activity for context.

\subsection{Data Analysis}

After the transcription of audio recorded on students problem solving process, the first analysis stage consisted on identify the themes observed throughout the transcript. We first attempted line by line coding Charmaz (2001), and described each turn according to its information and goal. After this, we revisited the descriptions to find common themes across the transcript, which led to defining five themes: 1) structure of the learning activity, 2) scientific narrative, physics concepts and principles 3 ) requests for information and feedback, 4) students' age, and 5) predicting students' behaviors. In order to reach inter-rater reliability, two additional research assistants were introduced into the codes and asked to code a section of the transcript independently. After this, the team of researchers reviewed and redefined the codes until further agreement according to codes' characteristics and presence in the data. Then, researchers proceed to an additional independent coding process of the whole section. This last coding process led to a Cohen's Kappa of .9 for inter rater reliability. Further, each of the five themes is explained in terms of its properties, conditions from where they arise, consequences on the evolving discussion, and relations with the others.

Finally, analysis was conducted to find the degree to which the group process met the conditions of group effectiveness (Hackman 1987). For this analysis we used field notes along with the transcript of the problem solving process to identify sources of motivation and engagement, participation, roles and group processes to find if whether the task, educational context and group work approximate to an effective. Given that there was no formal assessment of motivation to perform the activity administered to the group, evidence of motivation is operationalized as a function of corporal language and disposition on the table where the group is working, frequency of contributions during group discussion, and explicit messages of either like or dislike. Accordingly we operationalized high motivation as evidence of a high frequency of contributions, in combination with a physical disposition that suggest engagement in the activity, like 


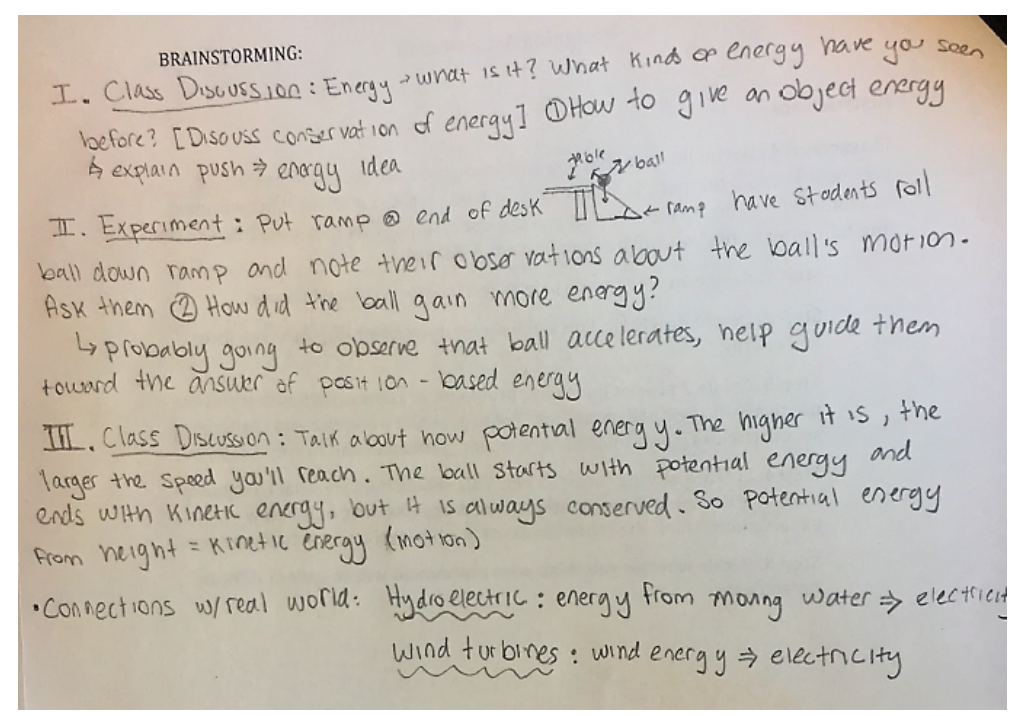

Figure 1. Ideas and decisions made for the learning activity.

leaning over the table, observing what other members are doing, and writing on the worksheet. In contrast, low frequency of contribution, as well as not looking at the group, or turning the chair to look to someplace else while other members are working might indicate low motivation.

\section{Results}

\subsection{Emergent Themes}

We identified five themes taken from the solution created by our focal group. Their activity was designed for primary students, and to encourage learning on the relationship between energy and motion. As seen in Fig.1, the group went beyond the simplicity of a learning activity and designed a lesson plan that included an initial class discussion for the targeted students to reflect on the concept of energy, relate to their prior experience, and connect it with motion through the concept of force. Later, there is an experiment consisting on having students rolling a ball down a ramp, and observe the change in energy in connection with the change in speed while the ball is going down. Finally, the third stage in their lesson plan includes a more formal introduction of potential and kinetic energy, their respective characteristics, and connections with real-world examples in hydroelectric plant and a wind turbine.

To create this lesson plan, the group addressed four important themes related to: 1) structure of the activity; 2) scientific narrative of the activity; 3) targeted students age and prediction of behaviors on the activity; and 4) requesting information and feedback. The first three themes are derived from the group discussion to orient the task towards decision-making, while the last theme enabled such decision upon collective agreement. Table 1 provides examples of each of these themes, and their frequency of occurrence. Following, we present and describe each theme based on unique characteristics, however, their nature and impact are intertwined for the final goal of creating the learning activity. 
Table 1. Themes, Examples and Frequency of Emergence in the Transcript

\begin{tabular}{|c|c|c|}
\hline Themes & Examples & Frequency \\
\hline Structure of the activity & $\begin{array}{l}\text { "And then we could be like: OK, why do you } \\
\text { think that we don't just sink into the Earth? } \\
\text { Why are we not continually sinking towards the } \\
\text { center?" }\end{array}$ & $59(45.38 \%)$ \\
\hline $\begin{array}{l}\text { Scientific narrative of } \\
\text { the activity }\end{array}$ & $\begin{array}{l}\text { "How do you give an object energy? Like oh, } \\
\text { pushing it."; "The burning heats and expands } \\
\text { like you ignite the gasoline in a car and it ex- } \\
\text { pands a piston and does." }\end{array}$ & $31(23.85 \%)$ \\
\hline $\begin{array}{l}\text { Targeted students age } \\
\text { and prediction of behav- } \\
\text { iors on the activity }\end{array}$ & $\begin{array}{l}\text { "But that's like, again for older kids, and our } \\
\text { kids."; "These kids can understand that. Then } \\
\text { most of them would say like you push it or you } \\
\text { pull it, or you move it." }\end{array}$ & $18(13.84 \%)$ \\
\hline $\begin{array}{l}\text { Requesting information } \\
\text { and feedback }\end{array}$ & $\begin{array}{l}\text { "So do we want to just tell them about it?"; } \\
\text { "You want to do that in the beginning?"; "But } \\
\text { then we don't want to give them those formulas } \\
\text { right?" }\end{array}$ & $22(16.92 \%)$ \\
\hline
\end{tabular}

\subsubsection{Structure of the Activity}

As seen in Table 1, the most frequent theme is negotiating the structure of the learning activity. Transcript coded with this theme includes discussion of group members working to provide the task with an adequate structure for the targeted students to build deeper understanding on the decided content knowledge: force and energy transformation. As seen on Fig. 1, the elements decided for the structured of this activity include a sequence of class discussion, experimentation, and a final discussion. The set of activities described by the participants were designed to engage and facilitate younger students' learning on the mentioned physics concepts and principles. This theme reflects the mediation of implicit individual intentions, understandings of what a learning activity is, and predictions of what students may do, all oriented towards an appropriate organization of the scientific/pedagogical narrative for the activity. Further, the degree to which members' notions of what a lesson should be like, its purpose, as well as their predictions regarding which features could make students to experience a meaningful learning experience are in constant interaction with the other identified categories. For instance, deciding to use force and motion, or conservation of energy instead, or targeting elementary instead of middle school students would have affected the possible activities/questions and the way these would have been presented. Moreover, an explicit example of this is depicted in the following dialogue between Anna and Allan, where they mediate the lesson's structure once identified and decided to address mechanical energy:

(1) Anna: "OK. So the first activity would be, the discussion? Or like.... And then the second could be the experiment? (Pause) Maybe... do brainstorm first."

(2) Allan: "I think maybe something like, the ball rolling down the hill, and a discussion of its energy and, what, are we talking about energy."

(3) Anna: "Yeah. OK. So the first thing that would do is just set up the activity and then would tell the kids, OK! Remember last time when we were doing this activity and (unintelligible), but now we are going to do this, and then they could measure the speed, right?"

Here Anna suggests and asks for approval to include a discussion as a first step for 
the activity, followed by observation and experimentation. However, Allan seems more inclined towards starting with experimentation. Within the context of the discussion, the key questions that the group is using to build their lessons are: "How do you give energy to an object?"; and "How did the ball gain more energy?". Both questions relate to the nature of energy as a property of bodies in motion and at a certain position (height) referenced to the ground, and how this is transformed by interactions (e.g., gravity). In contrast to Anna's idea, Allan implied that observing a "ball rolling down the hill", and not knowing where is getting its energy from may generate the cognitive conflict that could encourage students in discussing and brainstorming ideas. Anna's initial deductive approach for the task implies first addressing the concepts of energy and how it is transformed due to interactions, to then proceed with the experiment, and observed an example of this phenomenon. We consider Anna's approach to be deductive in the sense that the activity moves from an abstract representation or introduction of concepts and principles, to a particular physical situation where the different types of energy and interactions are observed. Compared to Anna's approach, Allan's is inductive, or inquiry-based, in that aims to use the observed phenomenon of a ball moving down a hill to define kinetic and potential energy, and how these are transformed while the ball is moving down. Furthermore, the extent to which group members understand the pedagogical implications of whether use a deductive or inductive approach remains unknown due the lack of evidence in this regard. However, both approximations to the problem reflect interesting reflections over the nature of the content, and the implications for its learning, which is encouraging within the context of the course and its education-oriented goal.

\subsubsection{Scientific Narrative of the Activity}

The second emergent theme relates to members explaining physics phenomenon for the purpose of the learning activity, including a mediation of the concepts, principles and characteristics to be included in it. Addressing the scientific elements for the activity became important for overcoming the initial conflict of facing a problem without a unique and right answer. The first contributions were made to explicitly verbalize surprise or lack of comfort regarding the open-ended nature of the problem. For instance, Anna's initial statement, "Maybe we could do like, Oh my god! There are so many things we could do," is evidence of this. Later on, and once the group acknowledged that the problem will require them creating and designing questions, there was an immediate intention to narrow the possible outcomes by using physics situations from previous classes, as well as their experience as physics majors. During the initial brainstorming process the group suggested ideas like holding a pencil and identifying the forces acting on it (gravity and normal force); balls with different masses rolling down a hill; swinging a bucket of water to understand inertia. However, a further constraint emerged when Anna stated that these examples would be better for older kids (i.e., targeted students). In similar fashion, the group utilized and kept on proposing physics-related phenomenons to frame the learning activity, as it allowed members to narrow down the unscripted scenario, by suggesting arguments on the concepts and principles for the task. The following ideas gave the impression that the content to use for the activity was gonna be forces, but then Allan intervened with "What is it that give energy?", which shifted the direction of the discussion toward the relationship between energy and motion, through the effect of forces.

The scientific nature of this theme focuses on sharing accurate explanations and examples based on Newtonian mechanics, particularly using the role forces play in 
transforming the energy of moving bodies through mechanical work. This is essential for the final purpose of designing an appropriate activity for learning motion and energy. Next, negotiating the content to address in the learning activity offers a connection between an accurate physics understanding and the intention of transferring this knowledge into a learning context that may be useful for others. The following interaction depicts an examples of this connection, when Anna and Jeff present arguments to provide scientific, pedagogical and methodological evidences to support the use of a body moving down a ramp as a simple but effective phenomenon to engage students:

(1) Anna: “... Let me see this P versus time stuff... This idea is cool. When they are trying to pushing the car, when is the push happening? You know what I mean? We could do stuff like that... Like, what they think is the motion of something that we've pushed. Like a can or something that's rolling. It could be like a graph. Or you know, draw a picture of what they think is happening."

(2) Jeff: "And then you have, you know, you push the thing and then falls down. Like, you push it and go some (unintelligible) ground. So obviously while you're pushing it it's accelerating, and then it's constant, and you have the slope that goes down. And then it falls, starts to roll and you notice oh! Hey look! It's accelerating but no one is touching it! Like (unintelligible) the force acting on it."

Although Anna's idea may seem related to the narrative of the learning activity, given her clear intention of using the cart experiment to draw evidence that would help engage and guide a discussion regarding to the role of gravity, or a push (force) in acceleration, it helps to contextualize the following arguments in favor of why conservation of energy should be the key principle to be addressed in the activity, and what phenomenon might work for this purpose. Finally, this discussion provides brief evidence of the appropriate understandings members have about gravity and energy transformation. It is assumed that friction is not an element of the discussion because the described experiment involves a cart rolling down a hill, which implies a rough surface (friction) that allows the wheel to roll down, otherwise the cart would slide (as opposed to roll) down. The presence of friction does not immediately violate the principle of conservation of energy on the cart, as the mechanical work due to this non-conservative force is zero given that the sections of the wells that are in contact with the rough surface are affected by static friction forces, not kinetic, and therefore, each of these points do not slide.

\subsubsection{Students' Age and Prediction of Behaviors on the Activity}

Deciding on school level of the targeted students to focus the activity became as challenging as selecting the content and the narrative for the activity. In several occasions participants suggested that certain experiments (e.g. Jeff: "... take different balls and rolling down the hill and see how far they go" , or Anna: "... that bucket of water trick where you swing it and then it doesn't fall?"), were either too boring for secondary students, or too difficult for younger ones. As notice, speculating over students' behaviors when facing a particular experiment or situation became an interesting strategy for decide over their age level. Both elements emerged to impose constraints regarding what an adequate practice would be for a particular group of students. Consequently, the group had to match the age of the targeted students, what they would potentially do and experience in the context of the activity, and if whether this was appropriate 
for them. Provide a meaningful learning experience taking in consideration their own understandings human development, as well as the targeted students unique developmental stage constituted a serious effort the group. In making sense of these ideas, after deciding on targeting middle school students, the content to address, and the initial experiment, the group agreed that students would easily notice that the ball moving down a ramp is accelerating (e.g. Anna: "It'll be obvious that the ball is going faster"). This observation should work as a motivation for further understanding what gravity is doing to the ball while this is moving down gaining speed. In this regard, Jeff suggested that after watching the ball going down and accelerating, students "need to start thinking about gravity. Like, gravity is doing some stuff, some cheeky stuff to make fall." Later on, the group went beyond this assumption, and agreed on how difficult would be for the middle school students to make the connection between gravity, the force that pulls objects down, and the transformation of potential energy into motion. As such, and to make this relation clear, they decided use direct instructions and explanations in the sequence of activities (See class discussion on Fig. 1).

\subsubsection{Requesting Information and Feedback}

The following theme involves members soliciting direct information or feedback regarding ideas to be included in the following turn. Throughout the coding of this theme, we noticed that the group developed implicit norms where the collaborative effort emerged as an opportunity to first, learn or clarify notions regarding the physical world, as well as learning processes by asking direct questions. And second, to democratically perform in a constructive and coordinated environment. First, by asking direct questions (e.g., Anna: "No other forces acting on it right?", members take advantage of others' expertise to either learn new scientific information, clarify their own ideas or the ones posted by others. This practice reflects Vygotsky's zone of proximal development (1987), in the sense that the group works as a platform where members are capable of developing understandings based on others' knowledge and experiences. This learning dimension of requesting information was not as frequent as the asking for collective agreement. This is reasonable given the nature of the physics ideas under discussion, and members' experience in physics, where content such as energy and motion are well understood by them.

In addition, requesting feedback allowed the group to find a common ground where to include restrictions and modifications into the design, but at the same time to socialize their own understandings regarding the purpose and goal of the activity. This theme is in direct connection with negotiating the structure of the activity and its scientific narrative, given the importance that requesting information and feedback for agreement has in collectively deciding the next step. This latter feature can be evidence when, at the beginning of the activity Jeff asks: "Wait, what are we even doing?" Where he requests the group for ideas to address in the task in order to start their work. An additional example comes from Anna when, she directly asks Allan for his opinion ("What do you think?") regarding the phenomenon previously discussed by Jeff and her, and if whether these were appropriate for the task. With this question, Anna's apparent goal is to engage Allan in the discussion after a period where she and Jeff were the only active participants. 
CONDITIONS FOR GROUP EFFECTIVENESS

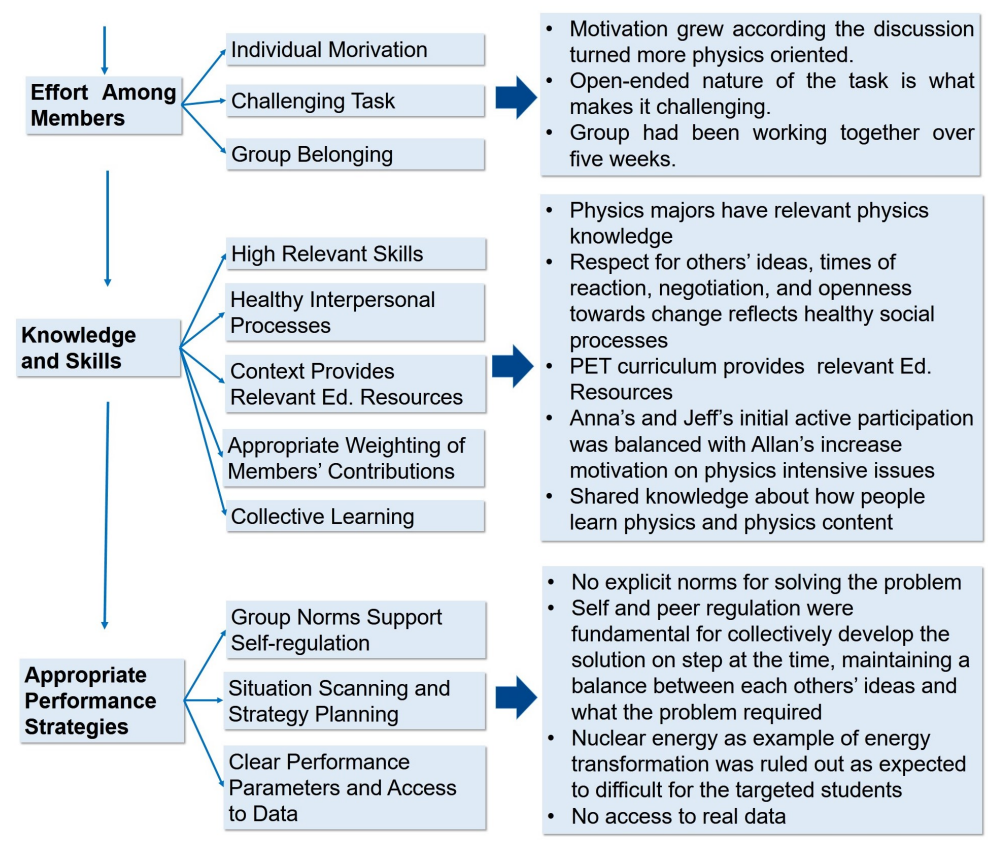

Figure 2. Conditions for group effectiveness and observed evidence.

\subsection{Conditions of Group Effectiveness}

In the context of a college course on conceptual physics and learning, it is important to identify the degree to which the environment, task, group composition and processes meet certain defined conditions that may lead to group effectiveness. Fig. 2 depicts the three levels of conditions for effective group performance, along with evidence observed in the data.

\subsubsection{Conditions that Support Effort}

Individual Motivation. Given that no formal assessment of motivation was administered in this study, we grounded this evidence on observations of corporal disposition of group members, in addition with the frequency of contributions and explicit messages regarding motivation. Initially, Anna and Jeff exhibited high motivation to solve the problem as they immediately started brainstorming ideas regarding students' school level, and different types of experiments and concepts. At this point, both participants were leaned over the table, looking at each other and the worksheet while exchanging ideas. In contrast, Allan remained silent during this first segment of the discussion, and only contributed with two short suggestions, one to critique Anna's idea of using gravity and forces as key topics for the activity (Allan: "That's a bit out of reach" ), and the other to respond to Anna's "What do you think?" by saying "Something simple". During this first section of the discussion all three students were leaned over the table, but without participating in the conversation. Allan's initial lack of interaction may be explained by the way he confronts these open-ended activities, particularly the ones where he is asked to be creative. In a different session, where the group was also asked to create two physics questions related to electricity and magnetism, Allan initially claimed that the activity was "Too open". Further, Allan stated "Personally I 
don't like being forced to be creative" when in a different opportunity group members were asked to individually create multiple physics related problems or questions. This evident lack of motivation for creative activities was not expressed by Anna and Jeff, who never claimed experiencing such unwillingness to generate ideas.

As the discussion and ideas unfolded into what the final design was going to be, Allan's engagement increased, evolving from silence and short contributions, to important scientific ideas. This transition towards effective engagement became evident as the ideas discussed by the group progressively shifted towards physics phenomena. It may be appropriate to suggest that there was an increase in motivation as soon as the brainstorming and activity reached interesting scientific levels. An additional reason for Allan's initial disengagement relates to the non-physics-intensive nature of the open-ended task at hand, which aimed for the group to design a learning activity, deciding upon topics and targeted students. From what was observed, of the three physics majors, Allan showed the highest tendency to make contributions regarding intensive physics issues, either about classes, problems, particular topics or applications in engineering. In consequence, Allan's motivation towards the activity grew according the discussion started addressing more and more physics-intensive issues.

In Anna's and Jeff's case, their degree of engagement and motivation remained fairly consistent throughout the task activity, as their willingness to participate, provide examples, ask questions and write down the best ideas (Anna) on the different analyzed themes was constant. Finally, the class context may have had an influence on members' motivation, because they were the only 'physics students' in the class, and their (selfimposed) expectations to perform according to certain level of expertise in their field may have either positively or negatively contributed to their motivation. According to Amabile's Amabile (1996) Intrinsic Motivation Principle of Creativity, external variables like reviewers' or peers' expectations, etc., are consider sources of external motivation that most likely have an impact on intrinsic motivation. In this context, the lack of high-physics dialogue among students on the class, given that physics was not an area of expertise for the majority of individuals in the class, could have lowered their expectations for how they should perform.

Challenging Task. The task was designed to push students towards creative collaboration and effectiveness. For this reason, the consideration of an open-ended activity within the context of teaching and learning physics was thought to be challenging and appropriate, as it pushed members to think and decide over diverse issues (e.g. students' school level, physics concepts and principles, pedagogical implications, etc.). The challenging nature of the task was evidenced at the beginning of the activity, where Anna and Jeff expressed their confusion and conflict with the problem by arguing that they could do anything due its open-ended nature. In simple words, difficulties are embedded within the openness and lack of constraints presented in the task, which forced subjects to mediate and develop an understanding of how physics concepts like gravity, energy and force could be understood for a particular group of students, and what might become a good and practical way of learning it. This latter feature is coherent with the goals of the class where the data was collected.

Group Belonging. At the time the data were gathered, the group had been working together under the same environmental conditions (e.g. day, time, location, instructor, class, etc.) for over five weeks. Therefore, it is fair to assume that the group had developed feelings of belonging and responsibility toward the task the group faced, as well as a reasonable level of coordination due to their time working together Rico et al. (2008). There were no signs that group members had experienced social discomfort during the session Furthermore, research evidence in teams performance has found 
that individuals tend to experience a sense of collective identity when identify salient attributes they have in common with other members Ashforth and Mael (2005). Consequently, the awareness of being the only three physics majors in the course is likely to have helped them to develop this sense of team identify.

The frequency of messages emitted by members aiming to complete the task suggests a degree of collective commitment towards high performance, which is related to the previously defined progressive motivation, as members' participation got richer and more fluid as discussion and constraints were defined and settled for what the final design would be. Evidence of this commitment towards group was expressed by some participants in the form of collective directions. Based on the latter arguments, we deemed reasonable to consider that group members experienced this collective identity, which in turn enable them a quality performance.

\subsubsection{Conditions that Support Knowledge and Skills}

High task relevant skills. The componential theory of creativity (Amabile 1996) suggest that task relevant processes (i.e., knowledge transfer, idea generation, etc.) as key elements for creative performance. Relevant processes allow individuals to build a cognitive style that enable the development of skills and knowledge (i.e., understanding the content), which if aligned in the direction of the collective flow, chances of members and group being creative may increase, due to coordination and effective communication. In the context of this particular group, each member had a certain degree of relevant physics knowledge, as they had taken several physics classes in their undergraduate training. Based on this, they have a reasonable understanding of the physics concepts and principles (physics-relevant skills) upon which they should design the learning activity (e.g. force, motion and energy). Evidence of content knowledge was observed throughout the discussion of the scientific narrative for the learning activity, where members proposed different scientific arguments for their potential inclusion in the lesson. As an examples of this, Jeff mentioned "Hey look! It's accelerating but no one is touching it;", when describing an object going down a hill. With this statement Jeff is alluding to the nature of gravity, and how it is different from other forces that required physical interaction or contact to produce the observed change in its motion (acceleration).

Moreover, as the task involved pedagogical notions for building knowledge, there are additional education-relevant skills that need to be appropriately use in designing a learning activity. This additional content knowledge and skills is fairly familiar to every member of the group, given their past and present experiences as students, and the notions they have been able to develop regarding characteristics of a 'meaningful' learning activity and the narrative and processes this may involve in the context of a science class (e.g. discussion, experimentation, etc.). Some of these educational/pedagogical notions are also supported by activities and the instructions provided in the class. Finally, there is no evidence indicating that group members have experienced formal education around learning issues besides what was addressed in this class.

Healthy interpersonal processes. At the time of data collection, the group has spent five almost 5 three-hour sessions working together, which may be considered a period of accommodation towards a healthy group dynamic and coordination, as mentioned earlier. Even though is not trivial to define what healthy group processes are, these may include respect for others' ideas and times of reaction, negotiation, and openness towards change in the direction of the discussion, as well as trust. These processes are observed every time an individual idea is proposed and discussed based on a team-level 
assessment regarding its appropriateness. Data does not show evidence of unhealthy rejections or negative comments towards others' ideas regarding the learning activity, suggesting that there is a fair degree of respect among members.

In more detail, roles and personalities are important for understanding the general evidences of healthy processes. In this context, Anna's and Jeff's apparent roles in the group tend to be similar, playing an active role in brainstorming ideas, and moving from well thought insights to off topic themes and jokes, whereas Allan seemed more reflexive and cautious in providing physics/engineering related ideas that might help for the final design. Here, the diverse nature of the contributions could be considered a challenge for Anna and Jeff, and vice versa for Allan, in that it may have led to the loss in group productivity during some segments of the discussion. Allan's initial lack of interaction might be understood as an attempt for free riding, production matching or evaluation apprehension, or evidence of production blocking by the group dynamic (Steiner 1972). Remember that free riders rest on the effort of others, considering that the group will be able to perform properly without their help. Similarly, production matching and evaluation apprehension refers to individuals comparing and monitoring their contributions with what others are proposing, and keeping ideas away from being shared with the group. Further, the interpersonal processes and collective coordination created allowed them to overcome these initial difficulties. For instance, recall Anna's direct question to Allan, where she called him to participate and engage in the discussion by asking him "What do you think?".

Context Provides Relevant Educational Resources. The materials and activities designed for the class are adapted from the Physics and Everyday Thinking (PET) curriculum (Goldberg, Robinson, and Otero 2006), which includes goals of developing scientific ideas and learning about how people develop scientific ideas. The objectives of the class and the activities performed are coherent with what students were asked to do for this study, which consisted in designing a physics learning activity using their scientific ideas along with their understandings of how people learn, in order to provide their product with both scientific and pedagogical structure. Therefore, the context where the activity was conducted provides opportunities for participants to acquire scientific and educational relevant skills for an appropriate performance on the task.

Appropriate Weighting of Members' Contributions. The frequency of emergent contributions delivered by each of the members was evenly distributed, according to their own roles within the creative dynamic, and the changing motivation throughout the task. As mentioned before, Anna and Jeff played a more active role in talking and providing ideas, showing constant motivation towards the task at hand. In Allan's case, his participation in the overall group interaction increased over time. In general, there is no evidence to support the claim of a particular member pulling the collective effort towards his or her direction, and minimizing others' ideas. In contrast, the healthy interpersonal processes developed for the group allowed them to fairly weight individual ideas and arguments for the purpose of group effectiveness.

Collective Learning. During the observations of group performance there were several instances where members requested information and feedback. At these moments members were able to gain knowledge regarding physics principles and interactions, as well as pedagogical decisions that would enhance students' learning possibilities. These situations naturally worked in favor of members' understanding regarding these issues. For instance, Jeff and Allan contributed to Anna's understanding of the presence of gravity in some particular interactions, when she explicitly asked for further clarification. Moreover, collective learning is assumed to be built by the group con- 
cerning the pedagogical implications of the activity, and the learning progression the targeted students are expected to experience throughout the task. This was observed when the group negotiated the structure of the task. The dialogue in page 5 between Anna and Allan shows evidence on this particular issue, in that starting the learning activity with an experiment is more appropriate than using a discussion as the initial motivator for the students.

\subsubsection{Conditions that Support Appropriate Performance Strategies}

Group norms support self-regulation, situation scanning, and strategy planning for a task with clear performance parameters, and access to data. We aggregate these three conditions in one description, and by doing so we achieve a more comprehensive explanation of how these conditional features enabled group performance.

Even though the group never verbalized a particular set of norms or strategies to solve the problem, some individual contributions provided explicit constraints to the problem (e.g. students' age) that regulated the creative process by enforcing certain conditions on appropriate ideas from group members. Accordingly, self- and peerregulation are key feature in the context of creative tasks, in that allowed members to perform within the group's parameters as a unit, developing each step at a time collectively, as well as maintaining a balance between individual and group decisions. Consequently, self-regulation, situation scanning, and strategy planning facilitated the collective agreements regarding the design of the learning activity, restricting ideas that were beyond the scope of the lesson, or the age of students. For instance, at some point of the discussion, and after reaching agreement about including a discussion section of conservation of energy and transformation from potential to kinetic when an object falls down from rest, Allan suggested adding other forms of energy transformation, like "windmills' motion" (rotational kinetic energy) to generate electricity, to which Jeff added solar or nuclear energy. With this new topic in mind, and following Allan's initiative, they decided that solar and nuclear would be "out of reach" for the group of students the activity was aiming for, and therefore, agreed to keep just the windmill phenomenon. This last example is evidence of situation scanning, and clarity about the parameters of the performance, which were under constant revision as the discussion and new alternative ideas were introduced. Yet, this stopped once the broader idea for the learning activity was decided, as group members kept track of what was expected for a good lesson plan in relationship to the content, materials, narrative, and students' age, and from there group members speculated over how the targeted students would behave (e.g. experimentation, idea-generation, etc.) as they engage on each stage of the activity.

Finally, assessing access to data implies taking into account the information embedded in the task and its goal. This information is accessible to students in the presentation of the task. Further information came from the learning context where the activity took place, thus leading to the use of knowledge regarding learning progressions, development of scientific models, and practice over multiple learning activities designed for elementary, primary and secondary students, over different physical phenomena. Beyond the mentioned available information, the task did not require the formal use of additional data. As noticed on the group's solutions (Fig. 1), the activities created are highly conceptual and imply qualitative descriptions of physics phenomena, without any type of mathematical manipulation. 


\section{Conclusions}

Generating problems is a real activity that the majority of educators are likely to engage, and as consequence demand the ability to generate, apply and select subjective assumptions in order to transform the ill-structured context into a well-defined one (Fortus 2008; Rietman 1964). The four themes that emerged from the analysis reflect the collective processes the group went through to solve the problem, and the particular characteristics of the task, as each theme echoes a particular discussion the group embraced to make decisions regarding every one of the issues involved in the activity. Moreover, these five themes represent interesting results linked to the role of idea-generation and creative thinking for solving process, which are important skills in today's education. Based on this evidence, an ill-structure activity like this pushes students to make decisions and argue over a sample of good and contrasting ideas, thus encouraging argumentation and reflection. One may expected that learning activities with a reduced set of restrictions (e.g., unscripted or open-ended task) would rise the number of issues discussed (themes) within groups, and the opposite would hold true if these conditions gradually increase towards well-structured problems with unique solutions. This an interesting and crucial attribute of ill-structured in the field of creativity and education. Further research needs to be done to deepen our understanding of the nature of these emergent themes in the context of open-ended problems, and test how consistent these may be across different groups.

Describing the conditions of group effectiveness in the context of the focal group allowed us to evidence the different ways in which the features of effectiveness took place. We claim that the learning environment, activity and group dynamic enabled effectiveness, yet, with important areas for improvement such as student motivation, group management, and clear strategies for solving the problem. Educators may take advantage of these features to effectively design learning activities that respond to the educational needs, but respecting the principles of collaboration. The conditions for group effectiveness can be useful in creating and monitoring safe environments for students to collaborate. This is coherent with the need of training on group management at university, given that students may have little to no formal training on how groups are supposed to work. For instance, addressing the importance of an appropriate weighting of members contributions may help students to recognize the damaging roles some members may enact (e.g., free rider), and regulate group effort over individual motivation to participate. Additionally, an scenario where students understand the importance of healthy interpersonal processes for communication of ideas and coordination may enable them the skills to manage conflict and damaging behaviors for an appropriate performance. A collective awareness over this dimension may constitute a strong motivator for self-regulation. Yet, in order for teams to develop social processes and understandings for an effective performance, teams need to work together for reasonable amount of time in task with high interdependence (?), like ill-structured problems that require decision-making. Consequently, training students over the conditions for group effectiveness, along with a curriculum based on activities high in positive interdependence (Johnson, Johnson, and Holubec 1986) is likely to guide students to control and understand the conditions under which they would build a positive and productive group experience.

Finally, we recognize the limitations of results, given that the evidence emerged from the analysis of one group, yet, we consider important to share these results as they provide a general sense and approximation to group performance on education. Future research must be conducted over multiple teams, in order to explore consistencies 
and differences in team processes, as well as whether these team-level behaviors vary depending on the nature of the curriculum. Among pedagogical innovations, researcher and educators may consider new mechanisms for group-level assessment, suggested important to encourage pro-social motivation, or the willingness to collaborate with others De Dreu et al. (2011).

\section{Funding}

This material is based upon work supported by the AAPT E. Leonard Jossem International Education Fund. Any opinions, findings, and conclusions or recommendations expressed in this material are those of the author(s) and do not necessarily reflect the views of the American Association of Physics Teachers.

\section{References}

Amabile, T. 1996. Creativity in Context. Boulder, CO.: Westview Press.

Anderson, C., and G.J. Kilduff. 2009. "Why do dominant personalities attain influence in faceto-face groups? The competence-signaling effects of trait dominance." Journal of Personality and Social Phys. 96 (2): 491-503.

Ashforth, B.E., and F Mael. 2005. "Social identity theory and the organization." Academy of Management Review 4: 20-39.

Baruah, J., and P.B. Paulus. 2008. "Effects of training on idea generation in groups." Small Research Group 39 (5): 523-541.

Benckert, S., and S. Petterson. 2008. "Learning physics in small group discussions- three examples." Eurasia Journal of Mathematics, Science, Technology Education 4: 121.

Byun, T., and G. Lee. 2014. "Why students still can't solve physics problems after solving over 2000 problems." American Journal of Physics 82: 906-913.

Charmaz, K. 2001. Contemporary field research. 2nd ed. Prospect Heights, IL: Waveland.

Csikszentmihalyi, M. 2013. Creativity: the psychology of discovery and invention. New York: Harper Perennial Modern Classics.

De Dreu, C. K. W., B. A. Nijstad, M. N. Bechtold, and M. Bass. 2011. "Group creativity and innovation: a motivated information processing perspective." Psychology of Aesthetics, Creativity and the Arts 5 (1): 81-89.

De Dreu, C.K.W., M. Baas, and B.A. Nijstad. 2008. "Hedonic tone and activation level in the mood-creativity link: Towards a dual pathway to creativity model." Journal of Personality and Social Psychology 94.

Fortus, D. 2008. "The importance of learning to make assumptions." Science Education 93 (1): 86-108.

Goldberg, F., S. Robinson, and V. Otero. 2006. "Physics and Everyday Thinking." .

Hackman, R. 1987. Handbook of Organizational Behavior. Englewood Cliffs, NJ: Prentice-Hall.

Harlow, J. J. B., D. M. Harrison, and A. Meyertholen. 2016. "Effective student teams for collaborative learning in an introductory university physics course." Physics Review Physics Education Research 12: 010138.

Heller, P., and M. Hollabaugh. 1992. "Teaching problem solving through cooperative grouping. Part 2: Designing problems and structuring groups." American Journal of Physics 60 (7): 637-644.

Hinds, P., K.M. Carley, D. Krackhardt, and D Wholey. 2000. "Choosing work group members: balancing similarity, competence, and familiarity." Org. Behavior and Human Decision Processes 81 (2): 226-251.

Johnson, D. W., R. T. Johnson, and E. J. Holubec. 1986. Circles of Learning: Cooperation in the Classroom. Edina: MN: Interaction. 
Kim, E., and S. Pak. 2002. "Students do not overcome conceptual difficulties after solving 1000 traditional problems." American Journal of Physics 70 (7): 759-765.

Leinonen, R., M. A. Asikainen, and P. E. Hirvonen. 2017. "Peer discussion in lectured-based tutorials in introductory physics." Peer discussion in lectured-based tutorials in introductory physics 13: 010114.

Pellegrino, J.W., and M.L. Hilton. 2003. Education for Life and Work: developing transferable knowledge and skills for 21st century. New York: The National Academies Press.

Rico, R., M. Sánchez-Manzanares, F. Gil, and C. Gibson. 2008. "The implicit coordination processes: a team knowledge-based approach." Academy of Management Review 33 (1): $163-184$.

Rietman, W. 1964. Heuristic decision procedures, open constraints, and the structure of illdefined problems. New York: Wiley.

Runco, M. A., and G. J. Jaeger. 2012. "The Standard Definition of Creativity." Creative Research Journal 24 (1): 92-96.

Shin, N., D. H. Jonassen, and S. McGee. 2003. "Predictors of well-structured and ill-structured problems solving in astronomy simulation." Journal of Research in Science Teaching 40 (1): 6-33.

Steiner, I. D. 1966. "Models for inferring relationships between group size and potential productivity." Behavioral Science 11: 273-283.

Steiner, I.D. 1972. Group Processes and Productivity. New York: Academic Press.

Sternberg, R.L. 2012. "The Assessment of Creativity: An Investment-Based Approach." Creativity Research Journal 24 (1): 3-12.

Van Der Vegt, G., and J.S. Bunderson. 2005. "Learning and performance in multidisciplinary teams: the importance of collective team identification." Academy of Management Review 48 (3): 532-547.

Vygotsky, L. S. 1978. Mind in Society: the Development of Higher Psychological Processes. Cambridge, MA: Harvard University Press. 